\title{
New insights into the stratospheric and mesosphere-lower thermospheric ozone response to the abrupt changes in solar forcing
}

\author{
Karanam Kishore Kumar, K. V. Subrahmanyam, and Sherine Rachel John \\ Space Physics Laboratory, Vikram Sarabhai Space Centre, Thiruvananthapuram-695022, India \\ Received: 16 May 2011 - Accepted: 14 June 2011 - Published: 22 June 2011
}

\begin{abstract}
Using a unique set of satellite based observations of the vertical distribution of ozone during the recent annular solar eclipse of 15 January 2010, we demonstrate for the first time, a complete picture of the response of stratospheric ozone to abrupt changes in solar forcing. The stratospheric ozone decreased after the maximum obscuration of the Sun and then gradually increased with time. A dramatic increase in stratospheric ozone of up to 4 ppmv is observed $3 \mathrm{~h}$ after the maximum obscuration of the Sun. The present study also reports for the first time the mesosphere-lower thermospheric ozone response to solar eclipse. Thus it is envisaged that the present results will have important implications in understanding the ozone response to abrupt changes in solar forcing and time-scales involved in such response.
\end{abstract}

Keywords. Atmospheric composition and structure (Middle atmosphere - composition and chemistry) - Meteorology and atmospheric dynamics (Middle atmosphere dynamics)

\section{Introduction}

Stratospheric ozone has been the cynosure for atmospheric scientists as well as common men as it protects life on the Earth by absorbing UV radiation from the Sun. Owing to its importance, several studies were carried out in the past to elucidate the variability of ozone at different time scales ranging from solar cycle (11 years) to planetary wave scales (few days) (Wirth, 1993; Logan, 1994; Fusco and Salby, 1999; Chandra et al., 1999; Chakrabarty et al., 1998). However, ozone variation during solar eclipse has been an interesting aspect of atmospheric research for many years. Solar eclipses provide a unique likelihood to verify our cur-

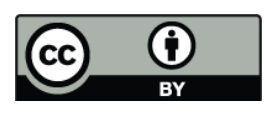

Correspondence to:

Karanam Kishore Kumar

(kishore_nmrf@yahoo.com) rent understanding of the ozone production and loss mechanisms and time scales involved in these processes. Most of the studies on eclipse induced effects on ozone focused on the total column ozone rather than its altitudinal distribution (Chakrabarty et al., 1997; Zerefos et al., 2000; Chudzynski et al., 2001; Tzanis, 2005). Most of these studies reported contrasting results. Bojkov (1968) reported an increase of total ozone near the greatest phase of the eclipse whereas Chakrabarty et al. (1997) reported that the total ozone measurements showed a sharp fall in the ozone column $10 \mathrm{~min}$ before the maximum obscuration of the sun, followed by a sharp rise $10 \mathrm{~min}$ later. Significant reduction in the total ozone as measured by Brewer spectro-radiometers during the course of solar eclipses has also been reported (Zerefos et al., 2000; Kazadzis et al., 2007). Very recently, Ratnam et al. (2011) reported the changes observed in temperature and ozone concentration in the lower stratosphere over Gadanki $\left(13.48^{\circ} \mathrm{N}, 79.18^{\circ} \mathrm{E}\right)$ associated with the annular eclipse of 15 January 2010. These authors observed unusual enhancements in temperature and ozone around $21 \mathrm{~km}$ just after the eclipse and these enhancements were attributed to large subsidence and horizontal advection. However, the ozone enhancement was quantified in terms of partial pressure rather than the mixing ratio which is a conserved quantity. As the partial pressure is directly proportional to temperature, an increase in the latter will result in an increase in the former. Thus it is always better to use mixing ratio to quantify the changes in ozone as a response to eclipse or any other process.

The secondary maximum of ozone concentration in the Earth's atmosphere is at mesospheric heights. Smith and Marsh (2005) investigated the processes responsible for the ozone maximum at the mesopause and its variability. They found that ozone variability is most dominated by the diurnal scale, which fluctuates between low concentrations in sunlight and high concentrations in darkness. Thus studies on processes responsible for ozone production, loss and

Published by Copernicus Publications on behalf of the European Geosciences Union. 

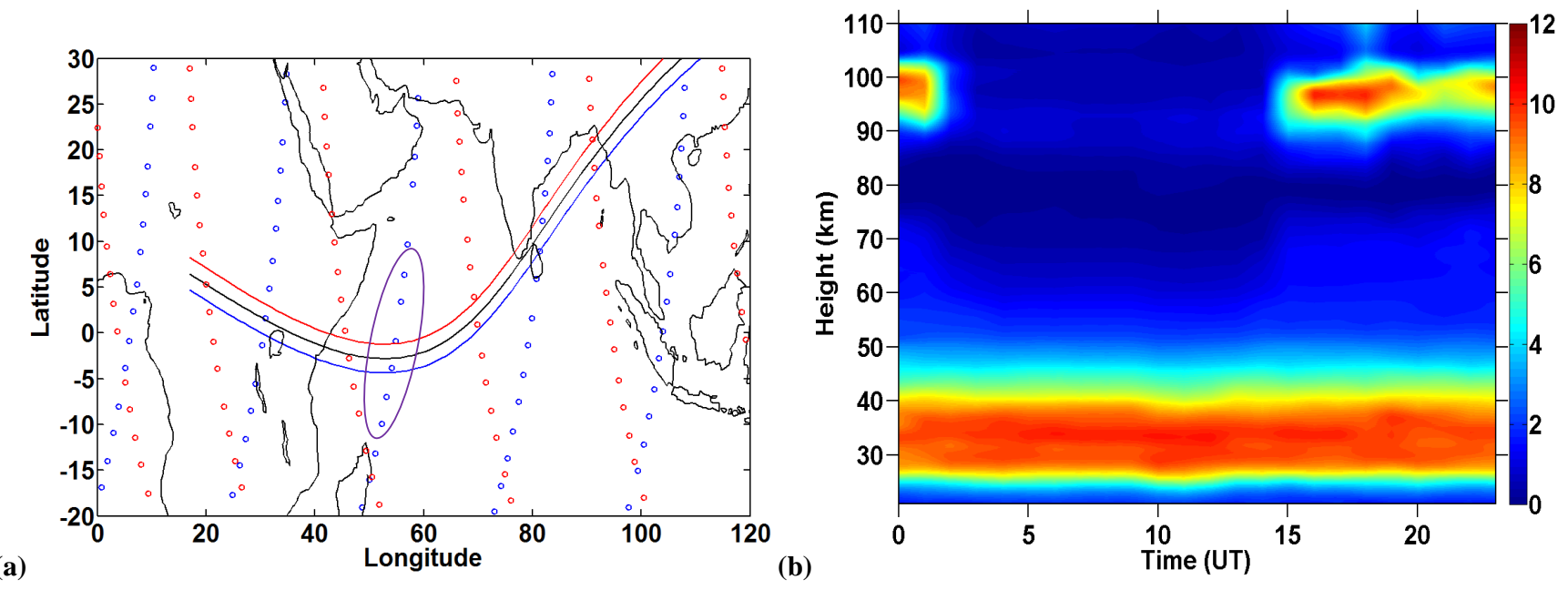

Fig. 1. (a) Path of annular solar eclipse of 15 January 2010 along with TIMED/SABER ascending (blue) and descending (red) orbits. The ellipse indicates the regions chosen for the present study and (b) Composite diurnal variation of ozone mixing ratio in the stratosphere and MLT region constructed using the SABER observations ozone during the winter of 2009-2010.

variability in both stratosphere and mesosphere are well understood and modelled. However, the time constants of these reactions and their response to abrupt changes in the incoming solar radiation are still a topic of research. Even though there are studies on total columnar ozone and stratospheric ozone during solar eclipses, the vertical distribution of ozone and its response to solar eclipse is relatively rare, especially in the mesosphere/lower thermosphere (MLT) region.

Each solar eclipse, depending upon its time of occurrence, duration and geographical location has a unique effect on the Earth's atmosphere. Solar eclipses provide a rare opportunity to study the response of the Earth's atmosphere to a step function kind of input. In this regard, the recent annular solar eclipse of 15 January 2010 caught the attention of several atmospheric and space scientists as it was the longest annular solar eclipse of the millennium. The central objective of the present study is to investigate the changes in the altitudinal distribution of ozone in the stratosphere as well as the MLT region during the annular solar eclipse of 15 January 2010 using the SABER (Sounding of the Atmosphere using Broad Emission Radiometry) instrument onboard the TIMED (Thermosphere, Ionosphere, Mesosphere Energetics and Dynamics) satellite. SABER is a limb viewing infra-red radiometer that measures the thermal structure and composition of the atmosphere from the upper troposphere $(10 \mathrm{~km})$ into the lower thermosphere $(120 \mathrm{~km})$ and one of the four instruments on board the TIMED satellite launched by NASA (Mlynczak, 1997; Russell et al., 1999). For the first time, the ozone response over a wide region experiencing various levels of obscuration of the Sun is studied and an attempt is made to generalize the response of ozone to the short-term changes in the solar forcing. The present study also reports the MLT region ozone response to the solar eclipse, which was never known. It is envisaged that the present study will provide some clue as to how ozone will respond to insolation blockade by volcanic eruptions, which injects tones of ashes deep into the atmosphere.

\section{Results and discussion}

The longest annular solar eclipse of this millennium occurred on 15 January 2010 and was visible in many parts of Uganda, India, Burma and China. Figure 1a shows the path of the annular solar eclipse overlaid by SABER ascending (blue circles) and descending (red circles) modes of observation. The three lines indicate the central (black), Northern limit (red) and Southern limit of the eclipse path. Keeping the eclipse path and the time of annularity in view, six observations (highlighted by an ellipse in Fig. 1a) over the Arabian Sea region $\left(10^{\circ} \mathrm{S}-10^{\circ} \mathrm{N}, 45-60^{\circ} \mathrm{E}\right)$ are chosen for further analysis. The details such as geographical latitude and longitudes, time of maximum obscuration, magnitude of the eclipse and the time at which SABER measurements were made are provided in Table 1 . It can be noted from the table that the time interval between the maximum obscurity and SABER observations decreases from South to North. Before examining the ozone profiles on the eclipse day, it is important to know the diurnal variation of ozone in the stratosphere and the MLT over the study region. As lower earth orbiting satellite observations cannot provide round the clock measurements, we have constructed the composite diurnal variation of ozone in the stratosphere and the MLT over the study region $\left(10^{\circ} \mathrm{S}-10^{\circ} \mathrm{N}, 50-60^{\circ} \mathrm{E}\right)$ using the SABER observations during Northern Hemisphere winter months (December-January-February) of the years 20092010 and is shown in Fig. 1b. From this figure, it can be seen that the maximum ozone mixing ratio reaches up to 
Table 1. Particulars of solar eclipse over Arabian Sea region.

\begin{tabular}{crcccc}
\hline S. No. & Latitude & Longitude & Maximum phase of eclipse (UT) & Magnitude & Time of SABER observations (UT) \\
\hline 1 & -9.8952 & 52.2632 & $05: 57: 18$ & 0.769 & $06: 32: 46$ \\
2 & -6.9877 & 53.1803 & $06: 01: 44$ & 0.866 & $06: 33: 05$ \\
3 & -3.8093 & 54.0784 & $06: 01: 52$ & 0.929 & $06: 34: 38$ \\
4 & -0.8556 & 54.8347 & $06: 11: 04$ & 0.909 & $06: 34: 58$ \\
5 & 3.3895 & 55.7995 & $06: 19: 36$ & 0.803 & $06: 36: 49$ \\
6 & 6.3835 & 56.3986 & $06: 25: 02$ & 0.732 & $06: 37: 8$ \\
\hline
\end{tabular}
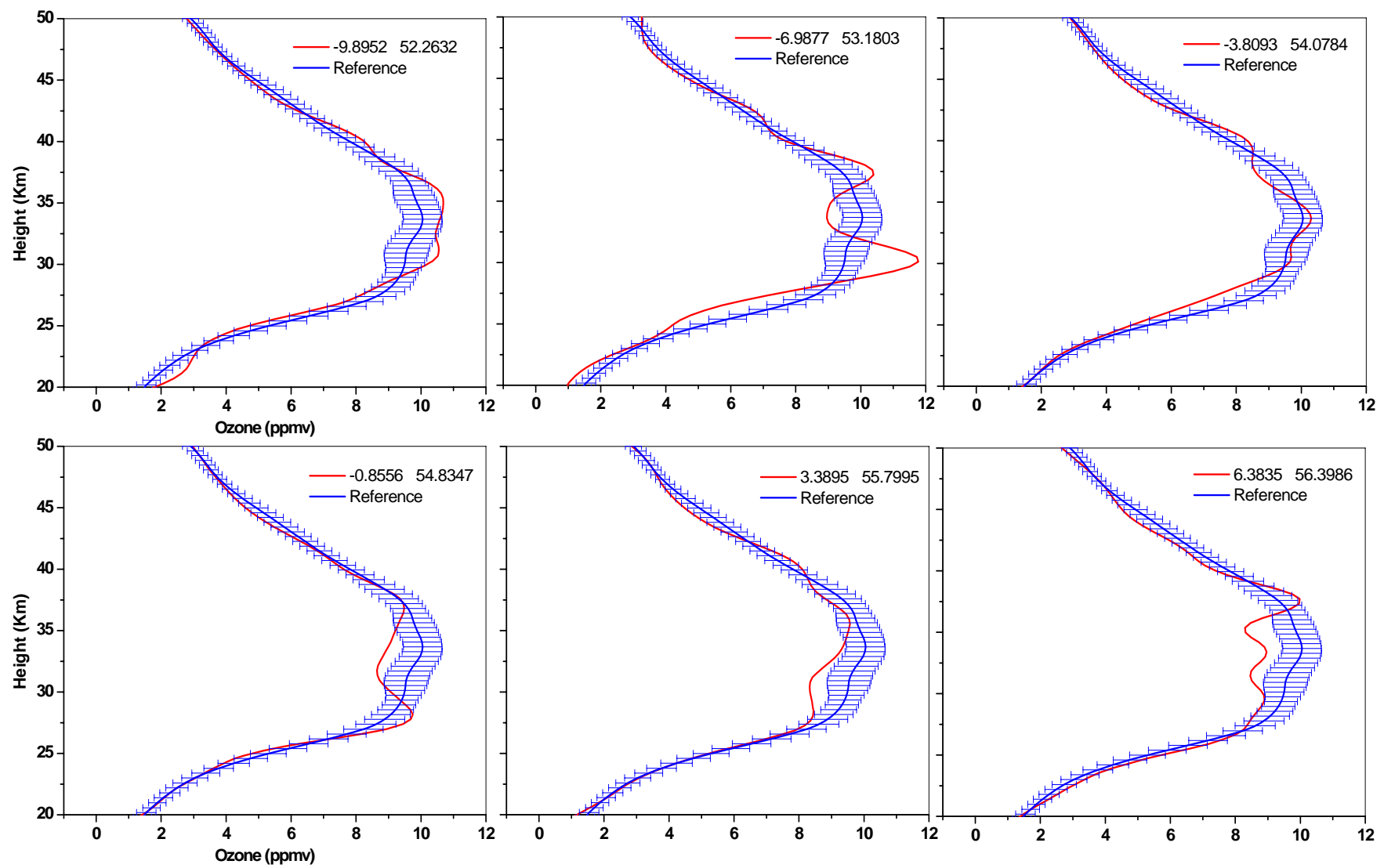

Fig. 2. Height profiles of ozone observed on the eclipse day (red) over the six regions under study along with reference profiles (blue). The horizontal bars in the reference profile indicate the standard deviation.

10 ppmv at an altitude of $30-35 \mathrm{~km}$ in the stratosphere. The ozone mixing ratio and the altitude at which it peaks do not show considerable variations within a day. However, mean removed diurnal variations show the intra-day variations in ozone mixing ratio up to $\sim 0.5 \mathrm{ppmv}$ in the stratosphere (figure not shown). On the other hand, the diurnal variation in the MLT ozone is very large. From Fig. 1b, it can be noted that the local night-time maximum in ozone reaches up to 10 ppmv $(\mathrm{LT}=\mathrm{UTC}+3.5 \mathrm{~h})$ in the MLT region and is comparable to the stratospheric ozone concentration. In the daytime, there is very low ozone concentration of the order of
0.5-1 ppmv in the MLT thus showing pronounced diurnal variation. The low concentration of day-time ozone in the MLT is attributed to fast reaction rates of photodissociation of ozone in the Schumann-Runge bands. Thus MLT ozone variability is dominated by the diurnal scale. More details of the MLT ozone and factors governing their variability can be found in Smith and Marsh (2005). Figure 1b thus provides diurnal variation of ozone in the stratosphere and the MLT over the region considered under the present study.

After obtaining the background ozone diurnal variations during winter months, ozone variation during the eclipse day 
(a)

(b)

(c)

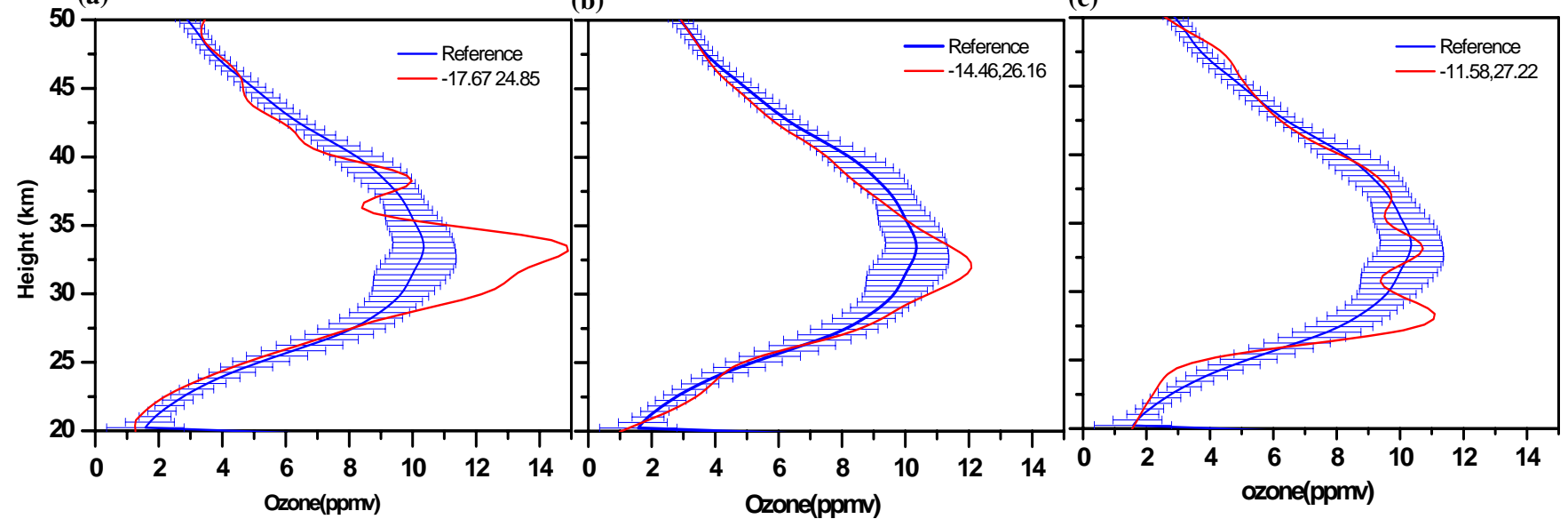

Fig. 3. Height profiles of ozone measured after $\sim 3 \mathrm{~h}$ of the maximum obscuration of the Sun over African region. Geographical locations are provided in the figure.

is analyzed. Figure 2 shows the height profiles of ozone mixing ratio over the six regions described in Table 1 . The reference profile is constructed using the SABER observations during January 2010 over the study region $\left(10^{\circ} \mathrm{S}-10^{\circ} \mathrm{N}, 50\right.$ $60^{\circ} \mathrm{E}$ ). Only those profiles measured during 6-8 UTh are used for constructing the reference profiles. It is to be noted that the magnitude of the eclipse is changing from one location to the other with maximum at $\left(-3.80^{\circ} \mathrm{S}, 54.07^{\circ} \mathrm{E}\right)$. The beginning of the eclipse was around 04:00 UTC and the end of the eclipse was after 08:00 UTC over this wide region. Thus all the profiles shown in Fig. 2 are those after the maximum obscurity of the Sun and before the end of the eclipse. The present observations are very rare in the sense that the ozone profiles are obtained during varying degrees of obscuration of the Sun within a short time period. At the same time, we have the reference profile obtained in the same month and during the same time of the day, which was lacking in many of the earlier ground based rocket/ozonesonde studies. From the first profile of Fig. 2, one can notice that there is a slight enhancement of ozone at its peak altitudes $(\sim 30-35 \mathrm{~km})$. The enhancement is significant as it is more than its day-to-day variability during those hours as indicated by the standard deviation. The second profile also shows a sharp enhancement at $30 \mathrm{~km}$, a secondary maximum at $37 \mathrm{~km}$ and a reduction in between these heights. In the third profile where the magnitude of the solar eclipse is maximum, surprisingly, there are no notable changes in the ozone profile and the variability is within the standard deviation. The rest of the ozone profiles (fourth, fifth and sixth) show significant decrease in magnitudes in the $30-35 \mathrm{~km}$ altitude region as compared to the corresponding reference profiles. Thus in general, as the time interval between maximum obscurity of the Sun and the SABER observation increases, we observe varying degrees of changes in ozone in the $30-35 \mathrm{~km}$ altitude region. The profiles observed relatively closer to the maximum obscurity (fourth, fifth and sixth) show decrease in ozone and the profiles (first and second) measured at slightly later times show increase in ozone. The third profile, which is observed over the maximum obscurity region, shows no significant change in the ozone concentration. Besides, the changes in ozone are more significant above $30 \mathrm{~km}$ when compared to the region below this altitude. This is obvious as upper stratospheric ozone is more sensitive to photochemistry as compared to lower stratospheric ozone. An ideal observation for quantifying the ozone changes with respect to the obscurity of the Sun should therefore be a time-series measurement with high temporal resolution. Nevertheless, the present observations provide some new insights into the ozone variability during an eclipse.

From the above observations, it is evident that the ozone in the stratosphere is changing as a response to eclipse and the increase or decrease of ozone with respect to the reference profile is dependent on the time of observation from the time of maximum obscurity. The decrease of ozone in the stratosphere can be straightway attributed to the reduced solar radiation, which results in decrease of photolysis of molecular oxygen and hence the production of atomic oxygen, which is essential for three body reaction involving molecular and atomic oxygen. Reduced production of atomic oxygen results in decreased ozone. At the same time, one should also expect an increase in ozone as photodissociation of ozone decreases due to reduced solar radiation. However, ultimately, increase or decrease of ozone depends on the balance between the photolysis of molecular oxygen and the photo dissociation of ozone. Thus the observed changes in ozone in the present study can be attributed to the imbalance between the photolysis of molecular oxygen and photodissociation of ozone. As mentioned earlier, the eclipse over the study region started at 04:00 UTC, which resulted in the depletion of atomic oxygen and also in the reduced photodissociation 

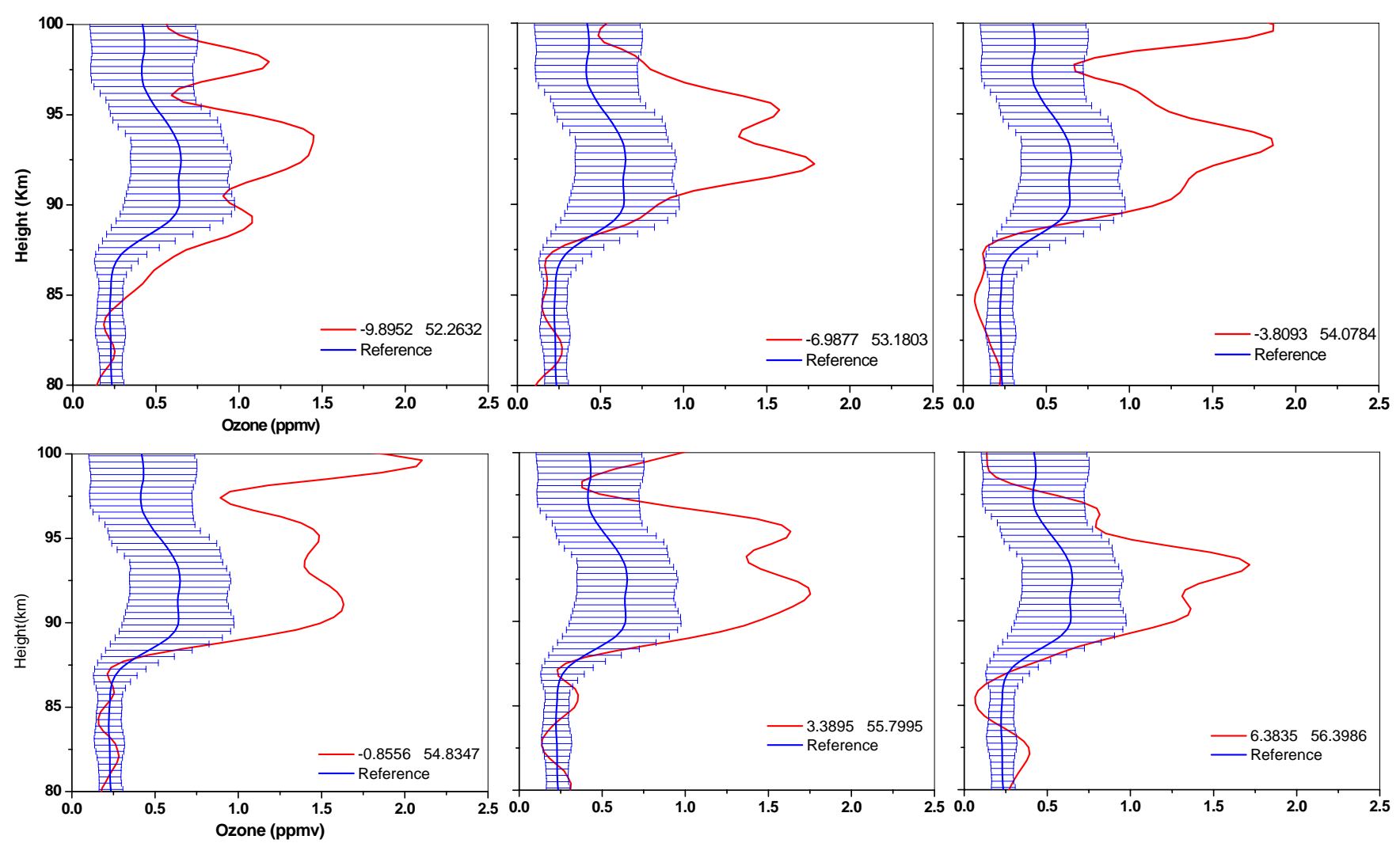

Fig. 4. Same as Fig. 2 but for MLT region.

of ozone. By the time ozone measurements were made by SABER, all these locations were experiencing various degrees of balance between the above mentioned processes. For example, over the first and second profile regions, the production of ozone is dominating as compared to its loss by photodissociation of ozone. Over the third profile region, where there are no significant changes in the ozone profile, both production and loss processes may be in equilibrium and over the rest of the regions, the reduction rate is dominating compared to the production rate. As these ozone profiles were sampled within few minutes, the present results emphasize the short time-scales involved in the shift of the equilibrium between the production and loss processes of ozone. Thus the present analysis brought out the eclipse induced changes in the vertical distribution of ozone in the stratosphere and for the first time emphasized the importance of the time at which the profile is measured and its consequences. As most of the earlier studies were based on ground based ozonesondes, the results might have depended on the time at which the ozone profile was measured with respect to the eclipse phase. It is now clear from the above discussion that the ozone concentration is increasing as the time of observation from the maximum phase of the eclipse is increasing.

To further substantiate this generalized statement, one should have ozone measurements well advanced in time with respect to the maximum obscuration. The first profile depicted in Fig. 2, which showed an increase in ozone with respect to the reference profile, was measured after $\sim 35 \mathrm{~min}$ of the maximum phase of the eclipse. It is also verified that the profiles measured to the south of first profile showed an increase in ozone and the profiles measured to the north of sixth profile showed a decrease in ozone (figures not shown). To know whether any measurements were available well after the eclipse, various orbits of the SABER are verified. There were measurements over the African region, where the maximum obscuration occurred around 05:30 UTC and SABER measurements were around 08:15 UTC. These measurements are best for verifying the above-mentioned generalized statement as well as to study the delayed effect of the eclipse. Figure $3 \mathrm{a}$ shows the height profile of ozone measured over $17^{\circ} \mathrm{S}, 24^{\circ} \mathrm{E}$ region along with the reference profile. This figure shows dramatic increase of ozone up to 4 ppmv with respect to the reference profile. This is the first time that an increase of this magnitude is observed during the eclipse day. One more profile measured over $14^{\circ} \mathrm{S}, 26^{\circ} \mathrm{E}$ is shown in Fig. 3b. This profile also shows an enhancement in ozone at its peak altitude; however, the magnitude of enhancement is less than that of Fig. 3a. It is to be remembered that the time of measurement (with respect to the maximum phase of the eclipse) of the profile shown in Fig. 3a is later 
than that of the profile shown in Fig. 3b. Thus these two profiles (especially Fig. 3a) show substantial increase in ozone concentration and support the general conclusion drawn in the present study that the ozone decreases initially and then increases while moving away from maximum obscuration in time.

Photochemistry alone cannot explain the magnitude of ozone enhancement observed in the present study. One should also consider the role of eclipse induced dynamics. It is known that Earth's atmosphere undergoes thermal contraction during solar eclipse events. The downward and subsequent upward motions do play a vital role in controlling the ozone chemistry. Recently, Wang and Liu (2010) emphatically showed the atmospheric thermal contraction associated with eclipse induced dynamics. These authors examined the temperature changes due to the total solar eclipse of 22 July 2009 and found that there was a warming in the upper troposphere and lower stratosphere. The warming was attributed to thermal contraction of the atmosphere, which induces downward movement in the upper troposphere and lower stratosphere and subsequent adiabatic heating. Ratnam et al. (2011) also showed warming around $21 \mathrm{~km}$ over Gadanki along with enhancement in ozone partial pressure. In the present study also, one should expect the eclipse induced downward motion. These downdrafts can be responsible for pushing the ozone/atomic oxygen downwards. As the time-scales involved in these processes are very short, one should have observations at specific time intervals to observe these phenomena. In the present set of SABER observations, there are ozone profiles which depict the downward movement of the ozone and one such profile is shown in Fig. 3c. This profile was measured over $11^{\circ} \mathrm{S}, 27^{\circ} \mathrm{E}$, which is subsequent to the profiles shown in Fig. 3a and b of the same orbit. From this figure, it is evident that the ozone peak has moved downwards, which can be attributed to thermal contraction of the atmosphere as a response to eclipse. However, these downward movements of ozone are not seen in other profiles shown in Fig. 2, which again emphasizes the importance of the time and spatial-scales involved in such processes. These eclipse induced downdrafts can redistribute ozone and other constitutes in the stratosphere such as atomic oxygen, which in turn reflects in the vertical profile of ozone. Thus eclipse induced photochemistry as well as dynamics are important in interpreting the ozone response.

The ozone profiles in the MLT over all the six regions mentioned in Table 1 are also analysed and shown in Fig. 4. The procedure used in the stratosphere to construct the reference profiles is used here too. Over all these six regions, ozone enhancement is observed in the $90-95 \mathrm{~km}$ height region during the eclipse day. This enhancement in ozone can be straightway attributed to the decrease in the rate of photodissociation of ozone due to reduction in solar radiation. It is known that in the MLT region, ozone is more abundant during the night-time as compared to day-time. The photodissociation of ozone in the MLT region is very fast, which is of the or- der of $100 \mathrm{~s}$. However, during the night-time, the life time of ozone is greater by one order of magnitude as compared to the day-time (Smith and Marsh, 2005). This is the prime reason for night-time maximum in the MLT ozone. The enhancement in MLT ozone observed in the present study can be due to the reduced photodissociaion of ozone during the obscuration of the Sun, which produces night-time like conditions. However, it is to be noted that the ozone mixing ratio during the eclipse is not the same as the night values. This is expected, as there will be diffused radiation during the eclipse and total night conditions will not be prevailing. Further, the enhancement in the MLT ozone is observed only over those regions which are highlighted in figure 1a but not over the other regions (highlighted in Fig. 3) where tremendous enhancement in stratospheric ozone is observed. Thus MLT ozone enhancement is short-lived confirming the shortlife time of day-time ozone as mentioned earlier. However, this is the first observational evidence for MLT ozone enhancement during a solar eclipse. Thus the present study brought out the changes in altitudinal distribution of ozone in the stratosphere and the MLT region simultaneously during the annular eclipse of 15 January 2010 and will have important implications in understanding the ozone response to abrupt changes in solar forcing.

\section{Summary}

Altitudinal distribution of ozone in the stratosphere and MLT region during the annular solar eclipse of 15 January 2010 is studied using SABER observations over the Arabian Sea and the African region. Six locations over which ozone profiles were available close to the maximum obscuration of the Sun are analysed to study the eclipse induced changes in the ozone. In general, the profiles measured close to the maximum phase showed decrease in ozone at their peak altitudes and profiles measured slightly later showed increase in ozone. These observations are explained on the basis of balance between ozone production and destruction processes. To substantiate this generalized statement, the ozone profiles measured after $\sim 3 \mathrm{~h}$ of maximum obscurity are also examined, which showed dramatic enhancement up to 4 ppmv in stratospheric ozone. The present study also emphasized the importance of the time of measurements of ozone with respect to the eclipse phase and their consequences. The MLT region ozone observations showed an enhancement during the solar eclipse, which is the first observational evidence. As the ozone maximum in the MLT region is predominantly in the night time owing to its longer life-time in the absence of solar radiation, the enhancement observed in the present study is attributed to reduced photodissociation of ozone.

Acknowledgements. Sherine Rachel John expresses her gratitude to ISRO for providing Research Fellowship. The authors acknowledge the efforts of the TIMED/SABER team in making the data available and freely downloadable. 
Topical Editor C. Jacobi thanks one anonymous referee for her/his help in evaluating this paper.

\section{References}

Bojkov, R. D.: The ozone variations during the solar eclipse of 20 May 1966, Tellus 20, 417-421, 1968.

Chakrabarty, D. K., Shah, N. C., and Pandya, K. V.: Fluctuation in ozone column over Ahmedabad, during the solar eclipse of 24 October 1995, Geophys. Res. Lett., 24, 3001-3003, 1997.

Chakrabarty, D. K., Peshin, S. K., Pandya, K. V., and Shah, N. C.: Long-term trend of ozone column over the Indian region, J. Geophys. Res., 103, 19245-19251, 1998.

Chandra, S., Ziemke, J. R., and Stewart, R. W.: An 11-year solar cycle in tropospheric ozone from TOMS measurements, Geophys. Res. Lett., 26, 185-188, 1999.

Chudzynski, S., Czyzewski, A., Ernst, K., Pietruczuk, A., Skubiszak, W., Stacewicz, T., Stelmaszczyk, K., Szymanski, A., Sowka, I., Zwozdziak, A., and Zwozdziak, J.: Observation of ozone concentration during the solar eclipse, Atmos. Res., 57(1), 43-49, 2001.

Fusco, A. C. and Salby, M. L.: Interannual variations of total ozone and their relationship to variations of planetary wave activity, J. Climate, 12, 1619-1629, 1999.

Kazadzis, S., Bais, A., Blumthaler, M., Webb, A., Kouremeti, N., Kift, R., Schallhart, B., and Kazantzidis, A.: Effects of total solar eclipse of 29 March 2006 on surface radiation, Atmos. Chem. Phys., 7, 5775-5783, doi:10.5194/acp-7-5775-2007, 2007.

Logan, J. A.: Trends in the vertical distribution of ozone: an analysis of ozonesonde data, J. Geophys. Res., 99, 25553-25585, 1994.
Mlynczak, M. G.: Energetics of the mesosphere and lower thermosphere and the SABER experiment, Adv. Space. Res., 20, 11771183, 1997.

Ratnam, M. V., Basha, G., Rojaraman, M., Mehta, S. K., Krishnamurthy, B. V., and Jayaraman, A.: Unusual enhancement in temperature and ozone vertical distribution in the lower stratosphere observed over Gadanki, India, following the 15 January 2010 annular eclipse, Geophys. Res. Lett., 38, L02803, doi:10.1029/2010GL045903, 2011.

Russell, J. M., Mlynczak, M. G., Gordley, L. L., Tansock, J., and Esplin, R.: An overview of the SABER experiment and preliminary calibration results, Proc. SPIE Int. Soc. Opt. Eng., 3756, 277-288, 1999.

Smith, A. K. and Marsh, D. R.: Processes that account for the ozone maximum at the mesopause, J. Geophys. Res., 110, D23305, doi:10.1029/2005jd006298, 2005.

Tzanis, C.: Ground-based observations of ozone at Athens, Greece during the solar eclipse of 1999, Int. J. Remote Sens., 26, 35853596, 2005.

Wang, K.-Y. and Liu, C.-H.: Profiles of temperature responses to the 22 July 2009 total solar eclipse from FORMOSAT3/COSMIC constellation, Geophys. Res. Lett., 37, L01804, doi:10.1029/2009GL040968, 2010.

Wirth, V.: Quasi-stationary planetary waves in total ozone and their correlation with lower stratospheric temperature, J. Geophys. Res., 98, 8873-8882, 1993.

Zerefos, C. S., Balis, D. S., Meleti, C., Bais, A. F., Tourpali, K., Vanicek, K., Cappelani, F., Kaminski, U., Tiziano, C., Stubi, R., Formenti, P., and Andreae, A.: Changes in environmental parameters during the solar eclipse of 11 August 1999, over Europe: Effects on surface UV 20 solar irradiance and total ozone, J. Geophys. Res., 105(D21), 26463-26473, 2000. 